\title{
Atrioventricular conduction system in hearts with muscular ventricular septal defects in the setting of complete transposition
}

The detailed structure of a ventricular septal defect was compared in 90 hearts with complete transposition (concordant atrioventricular and discordant ventriculoarterial connections) and in $\mathbf{1 0 2}$ hearts with concordant connections at both junctions; the latter group was selected to include only cases with the septums aligned in the normal way. The interventricular communications observed in $13 \%$ of the group with complete transposition, which, in our material, had no counterpart in the hearts with concordant segmental connections, were of special interest. These defects, completely surrounded by muscle, were positioned around the midline on the right side of the septum but always lay under or partially under the septal leaflet of the tricuspid valve. The medial papillary muscle group was always to the "left hand margin" of the defect as seen by the surgeon. Because these defects lay within the boundaries set by the septal leaflet of the tricuspid valve, they would conform to the criteria for classification as inlet muscular defects but could equally be described as central or subtricuspid. It is significant that, in all those cases with histologic sectioning, the axis of atrioventricular conduction tissue ran to the surgeon's right hand margin. This position is markedly different from the pattern found in typical defects of the inlet septum, which are completely surrounded by muscle and extend to the posterior wall of the heart. In this more common situation, the conduction axis runs above the left hand margin of the defect. This finding has obvious implications for surgical treatment. (J THORAC Cardiovasc Surg 1994;108:9-16)

Audrey Smith, FIMLS, MPhil, PhD, ${ }^{\mathrm{a}} \mathrm{M}$. Gwen Connell, AIMLS, ${ }^{\mathrm{a}}$ Mark Jackson, $\mathrm{PhD},{ }^{\mathrm{a}}$

Fons J. Verbeek, MSc, ${ }^{\mathrm{b}}$ and Robert H. Anderson, BSc, MD, MRCPath,

Liverpool and London, England, and Amsterdam, The Netherlands

From the Institute of Child Health, University of Liverpool, Royal Liverpool Children's Hospital Alder Hey, Liverpool, Englanda; the Department of Anatomy and Embryology, University of Amsterdam, Amsterdam, The Netherlands ${ }^{\mathrm{b}}$; and the Department of Paediatrics, Royal Brompton National Heart and Lung Institute, London, England. ${ }^{\mathrm{c}}$

Supported by the Endowment Fund of the Royal Liverpool Children's Hospital (A. S. and, in part, M. G. C.) by the British Heart Foundation (M. J., R. H. A., and, in part, M. G. C.); in part by The Netherlands Project Team for Computer Science Research, SPIN (project Three Dimensional Image Analysis) (F. J. V.).

Received for publication June 28, 1993.

Accepted for publication Jan. 9, 1994.

Address for reprints: A. Smith, PhD, Department of Anatomy, Institute of Child Health, University of Liverpool, Royal Liverpool Children's Hospital Alder Hey, Eaton Road, Liverpool, L12 2AP, England.

Copyright 1994 by Mosby-Year Book, Inc.

$0022-5223 / 94 \$ 3.00+0 \quad \mathbf{1 2} / \mathbf{1} / \mathbf{5 4 5 3 0}$ ne of the most important features of a ventricular
septal defect that a surgeon seeks to establish during
corrective operations is its relationship to the axis of
specialized tissue responsible for atrioventricular conduc-
tion. Although categorizations of ventricular septal
defects have been many and varied, ${ }^{1-9}$ recent consen-
sus has been that, from the surgical standpoint, the most
significant defects to differentiate are the perimem-
branous and muscular defects opening in subtricuspid
position to the inlet of the morphologically right ven-
tricle. ${ }^{10}$ This consensus has come about because, as
shown initially by Truex and Bishof ${ }^{11}$ in isolated defects
(a finding confirmed by Latham and Anderson ${ }^{12}$ ), the
atrioventricular conduction axis is found to the right hand
of the surgeon relative to the perimembranous defect
when viewed through the tricuspid valve but to the
left hand margin of the muscular inlet defect. The study
of Bharati and Lev ${ }^{13}$ showed that a similar arrange- 
Table I. Comparability of defects

\begin{tabular}{|c|c|c|c|c|c|c|c|c|}
\hline & \multicolumn{4}{|c|}{ Perimembranous } & \multicolumn{4}{|c|}{ Muscular } \\
\hline & \multicolumn{2}{|c|}{$\begin{array}{c}\text { Concordant } \\
V A \text { connections }\end{array}$} & \multicolumn{2}{|c|}{$\begin{array}{c}\text { Discordant } \\
V A \text { connections }\end{array}$} & \multicolumn{2}{|c|}{$\begin{array}{l}\text { Concordant } \\
V A \text { connections }\end{array}$} & \multicolumn{2}{|c|}{$\begin{array}{c}\text { Discordant } \\
V A \text { connections }\end{array}$} \\
\hline & & $C T$ & & $C T$ & & $C T$ & & $C T$ \\
\hline Inlet & 35 & 2 & 11 & 2 & $5^{*}$ & $2^{*}$ & $5^{*}$ & $1^{*}$ \\
\hline $\begin{array}{l}\text { Inlet not extending } \\
\text { to posterior wall }\end{array}$ & - & - & - & - & - & - & $12 \dagger$ & $3 \dagger$ \\
\hline $\begin{array}{l}\text { Trabecular outlet with } \\
\text { overriding pulmonary } \\
\text { valve }\end{array}$ & - & - & $10 \dagger$ & $1 \dagger$ & - & - & $7 \dagger$ & 一 \\
\hline Outlet & 13 & 3 & 1 & - & 4 & - & 6 & 1 \\
\hline Doubly committed & 1 & - & - & - & 1 & - & 2 & - \\
\hline Trabecular & 17 & 3 & 14 & 2 & 9 & - & 18 & - \\
\hline Confluent & 10 & - & - & - & - & - & - & - \\
\hline Multiple & - & 一 & - & - & 2 & 1 & 3 & - \\
\hline Total & 76 & 8 & 36 & 5 & 21 & 3 & 53 & 5 \\
\hline $\begin{array}{l}\text { Multiple mixed } \\
\text { perimembranous } \\
\text { and muscular }\end{array}$ & \multicolumn{4}{|c|}{5 (with concordant VA connections) } & \multicolumn{4}{|c|}{1 (with discordant VA connections) } \\
\hline
\end{tabular}

$C T$, Study of conduction tissue performed; $V A$, ventriculoarterial.

* Muscular inlet defect extending to the posterior wall of the heart.

$\dagger$ Associated only with ventriculoarterial discordance.

ment pertained when ventricular septal defects were found in the setting of complete transposition, which was the situation exemplified in the second edition of the textbook by Bharati, Lev, and Kirklin ${ }^{14}$ devoted to the surgical anatomy of the conduction tissues. We have now encountered a specific type of muscular ventricular septal defect in the setting of complete transposition that transgresses these well established rules. ${ }^{10,14}$ In this particular defect, which is subtricuspid when seen from the right ventricle but subpulmonary when observed from its left ventricular aspect, the conduction axis is found to the right hand of the surgeon approaching through the tricuspid valve. In this article, we discuss the anatomic features of this subtricuspid and subpulmonary defect found in the setting of complete transposition, emphasizing the features permitting its echocardiographic diagnosis.

\section{Material and methods}

The hearts used for this study were taken from the collection of pathologic material in the Institute of Child Health at the Royal Liverpool Children's Hospital Alder Hey. We examined 90 hearts with usual atrial arrangement, concordant atrioventricular and discordant ventriculoarterial connections (complete transposition), all with ventricular septal defect in which the atrial and ventricular septums were normally aligned. We compared these with 102 hearts with an isolated ventricular septal defect in the setting of concordant atrioventricular and ventriculoarterial connections and normally aligned septums. For classification, we used the system of Soto and associates, ${ }^{6}$ as modified more recently by Anderson and Wilcox. ${ }^{10}$ The margins of the defect were described as basal, apical, right hand, and left hand according to the view that would be obtained by the surgeon approaching through the right atrium and the orifice of the tricuspid valve.

The ventricular septal defects in 12 specimens with complete transposition were of special interest because they had no counterpart in our series with concordant connections. The defects in these hearts, all completely enclosed within the muscular septum, were central in relation to a midline drawn between the base and the apex of the right ventricle. They lay between the medial and posteroseptal papillary muscle complexes of the tricuspid valve. In the axis from base to apex, they lay under or partially under the septal leaflet of the tricuspid valve or its tension apparatus. The right hand margin did not extend either to the posterior (diaphragmatic) wall of the heart or to the posteromedial muscle. When viewed from the left ventricle, they opened in subpulmonary position. Three specimens from this group were selected for histologic study to determine precisely the course of the atrioventricular conduction tissues. ${ }^{15}$ Another 10 hearts from our series formed a group for comparison (five hearts with discordant and five with concordant ventriculoarterial connections). In these hearts, the ventricular septal defects were again enclosed by the muscle of the septum, but, in contrast to the previous group, the right hand margin extended to the posterior wall of the heart or to the posteroseptal muscle. These muscular defects communicated unequivocally between the ventricular inlets. Three examples of these defects were also studied histologically. A computer-assisted three-dimensional model was reconstructed of one example of each of the two types of muscular defect. This model permitted accurate superimposition of the axis of atrioventricular conduction tissue on to the photographs of the specimens.

\section{Results}

The defects present in both series, classified according to our current system, ${ }^{10}$ are indicated in Table I, which 
also shows the variations in proportions. Perimembranous defects appeared in $77 \%$ of the specimens with concordant ventriculoarterial connections but in only $40 \%$ with discordant ventriculoarterial connections. Of the defects in the setting of complete transposition, $68 \%$ were directly comparable with defects in the series of 102 hearts with concordant connections. In the remaining $32 \%$, the presence of malalignment, rotation, or hypertrophy of septal structures in the morphologically right ventricle created a structure in complete transposition that was not directly comparable with that seen in the isolated defects. In $19 \%$ of these hearts with complete transposition, malalignment of the outlet septum and overriding of the pulmonary valve were observed to be present in the same manner as has been well reported in the literature..$^{21-24}$ The ventricular septal defect in these hearts was sometimes perimembranous, but, in others, it had a muscular posteroinferior (right hand) margin. In the remaining $13 \%$, the defect, always enclosed within muscle, was either completely or partially covered by the septal leaflet of the tricuspid valve (Fig. 1). The left hand margin as seen through the tricuspid valve was either the posterior edge of the septomarginal trabeculation or its ramifications under the septal leaflet. In all these hearts, the anteroseptal commissure of the tricuspid valve and the medial papillary muscle complex were separated anteriorly from the left hand margin of the defect. The right hand margin did not extend to the posterior wall of the heart. When viewed from the left ventricle, the defect opened in subpulmonary position (Fig. 2). Occasional marginal fibrosis suggested attempted spontaneous closure. Defects with this location and structure were not identified among the 102 hearts with concordant segmental connections.

Nonetheless, a muscular defect with some comparable landmarks to the centrally located subtricuspid defect was seen in hearts both with and without complete transposition. In these subtly different defects, also completely enclosed by muscle, the anteroseptal commissure and the medial papillary muscle group again lay anterosuperiorly to the defect (Fig. 3), and, once more, the defect lay under or partially under the septal leaflet of the tricuspid valve. The surgeon's left hand margin was either the septomarginal trabeculation or the muscle of the inlet septum itself, depending on the size of the defect and the extent to which the septomarginal trabeculation encroached under the septal leaflet. In marked distinction to the previously mentioned type of defect, the right hand margin in this second group extended as far as the posterior wall of the heart or to the posteroseptal muscle (Fig. 3). Although the centrally located and the muscular inlet defects were both shielded by the septal leaflet of the tricuspid valve, their orientation through the ventricular

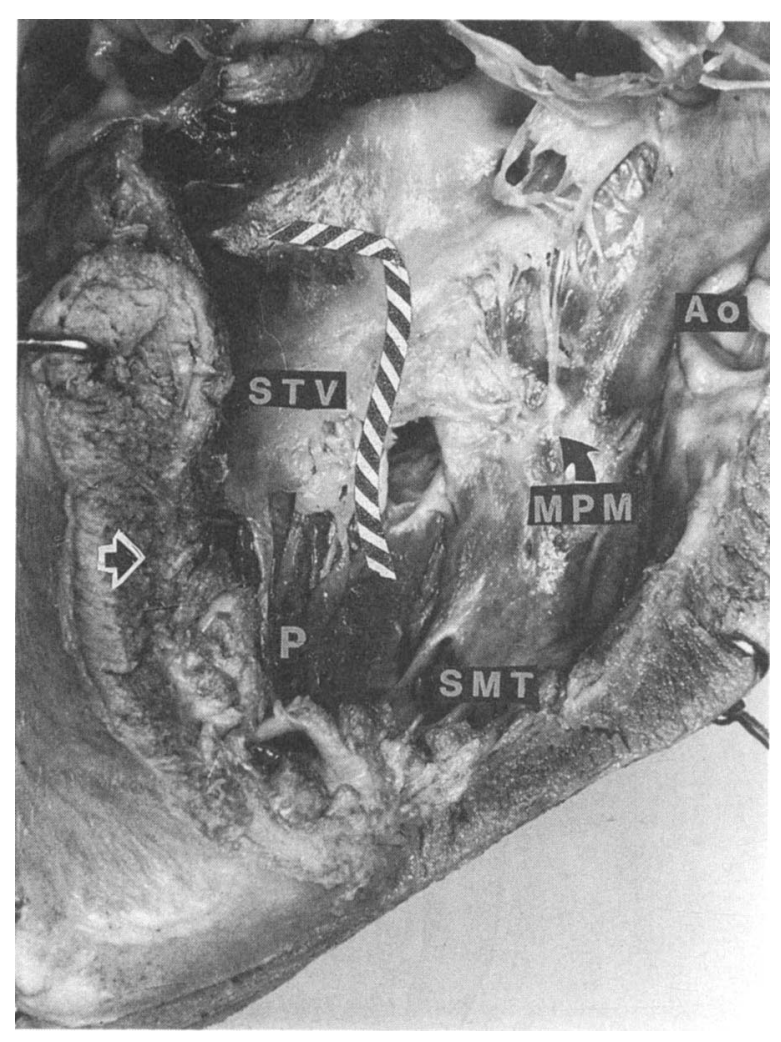

Fig. 1. Right ventricle of heart with complete transposition. Muscular ventricular septal defect lies between medial and posteroseptal papillary muscle complexes: it does not extend to posterior wall of heart (black and white arrow). Axis of conduction system (striped band) passes posteroinferiorly to defect. Ao, Aortic valve; $M P M$, medial papillary muscle complex; $P$, posteroseptal papillary muscle complex; $S M T$, septomarginal trabeculation; $S T V$, septal leaflet of the tricuspid valve.

septum gave them openings in different locations of the septum when viewed from the left side. The centrally positioned subtricuspid defects opened in subpulmonary position (Fig. 2), whereas the more typical muscular defect was positioned between the ventricular inlets (Fig. 4).

Specialized atrioventricular conduction system. In all the hearts that were sectioned, both with perimembranous and muscular defects, the atrioventricular node was found in its usual location within the apex of the triangle of Koch. The nonbranching atrioventricular bundle ran from the node toward the left side of the interventricular septum, in relation to the membranous septum when this structure was present. When it was absent, as in some cases with discordant ventriculoarterial connections, it ran through the central fibrous body (Table II). The bundle continued either intramuscularly or subendocardially toward its bifurcation. The left bundle branch 


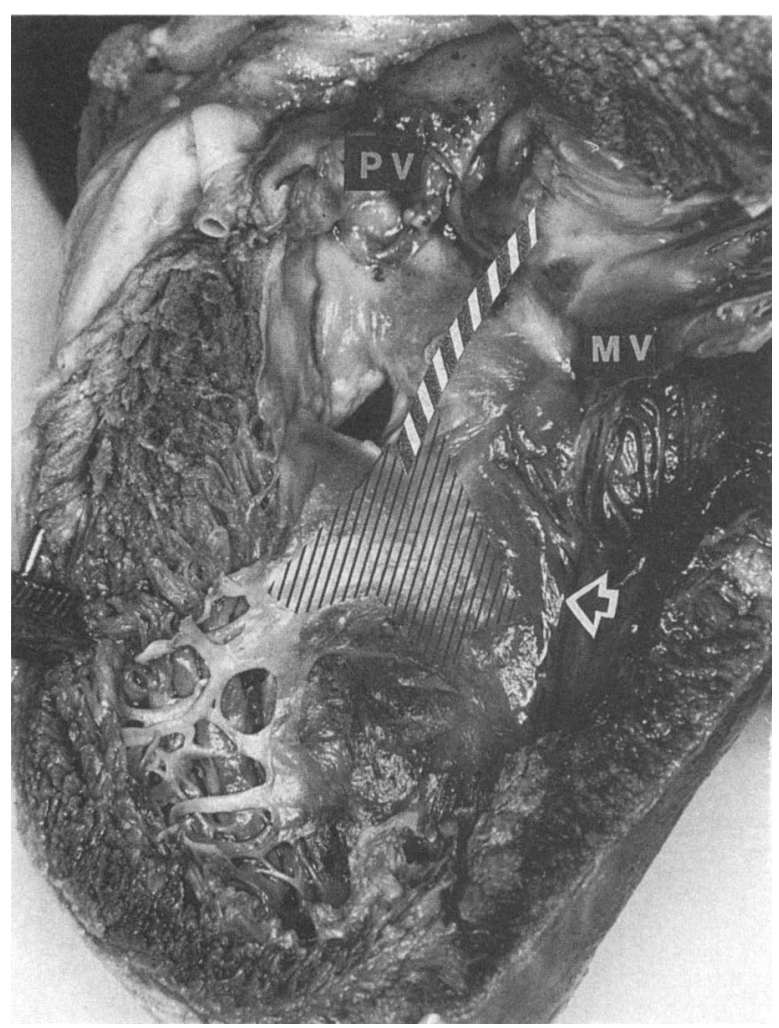

Fig. 2. Left ventricle of specimen in Fig. 1. Ventricular septal defect opens into subarterial position. Junction of septum with posterior wall of heart is indicated by arrow. Axis of conduction tissue runs posteroinferiorly to defect. $M V$, Mitral valve; $P V$, pulmonary valve.

always cascaded down the left side of the ventricular septum in the usual way. In the defect that opened in subpulmonary position when seen from the left side, the axis of the conduction tissue ran mostly intramyocardially to the right hand margin as viewed by the surgeon through the right atrium (Figs. 1 and 5). The bifurcation of the bundle itself was either on the margin of the defect (one heart) or close to it (two hearts). In contrast, in the muscular inlet defect that ran to the posterior wall of the heart, the axis of the conduction tissue ran closely to but not onto the left hand margin (Figs. 3 and 6). Table II compares the course of the conduction tissue in the two types of defect. In one heart with a muscular inlet defect, the posterior ramifications of the left bundle branch extended onto the left hand rim of the defect (Fig. 4).

\section{Discussion}

Our present findings, for the most part, support the work of previous investigators in showing that some types of ventricular septal defects are distinctive in the context of complete transposition. ${ }^{16-19}$ These defects by and large are readily described within our basic classification and follow well the accepted rules for prediction of their relationship to the conduction axis. ${ }^{10,14} \mathrm{We}$ observed one specific type of defect, however, that did not fit into previously described patterns. Thus, all of these defects occupied a subpulmonary position in the left ventricle, but when viewed from the right side of the septum, they lay between the medial and posteroseptal papillary muscle complexes, with the left hand margins being formed by the septomarginal trabeculation. In this respect, they resembled the typical muscular inlet defect. Unlike the inlet defect, however, the right hand margin never extended to reach the posterior wall of the heart or the posteroseptal muscle. This defect also differed from the typical central defects described previously in the literature, particularly in complete transposition, ${ }^{17,18}$ in that it was always located under or partially under the septal leaflet of the tricuspid valve. This feature also differentiates the defect from the central isolated muscular defect described by Wenink, Oppenheimer-Dekker, and Moulaert, ${ }^{5}$ which was said to lie at a considerable distance from the tricuspid valve and was "extremely rare in transposition."

From the surgical standpoint, the important point about these defects is that, in all three examples studied histologically, the atrioventricular conduction axis was found to run to the surgeon's right hand when viewed through the tricuspid valve. This distinction is important because, as discussed, the defect, when seen from the right side of the septum, bears marked similarities to the more frequently recognized muscular inlet defect. ${ }^{10,}{ }^{14}$ The latter defect, seen on the right side of the septum, has also been described as the posterior muscular type ${ }^{5}$ and is seen in hearts with both concordant and discordant ventriculoarterial connections. The essential difference from the subtricuspid and subpulmonary defect is that the right hand margin of the muscular inlet defect usually extends either to the posteroseptal muscle or to the posterior wall of the heart. Hoyer and associates ${ }^{18}$ did not illustrate their muscular inlet defect, but they did point out that, in such a defect, the conduction tissue runs to the left hand margin. This structure was confirmed in examples we sectioned for this study and was previously demonstrated by Bharati and Lev. ${ }^{13}$ In contrast, in the muscular defect with a subpulmonary left ventricular orifice, the conduction axis is to the right hand of the surgeon.

This finding is of crucial importance because Bharati and Lev, ${ }^{13}$ after their histologic study of five hearts with complete transposition and ventricular septal defect, reached the conclusion that, although subtle differences were present for the course of the atrioventricular conduction axis compared with hearts with concordant ventriculoarterial connections, the basic disposition was comparable in the two groups. ${ }^{11,12}$ We were well aware of this 


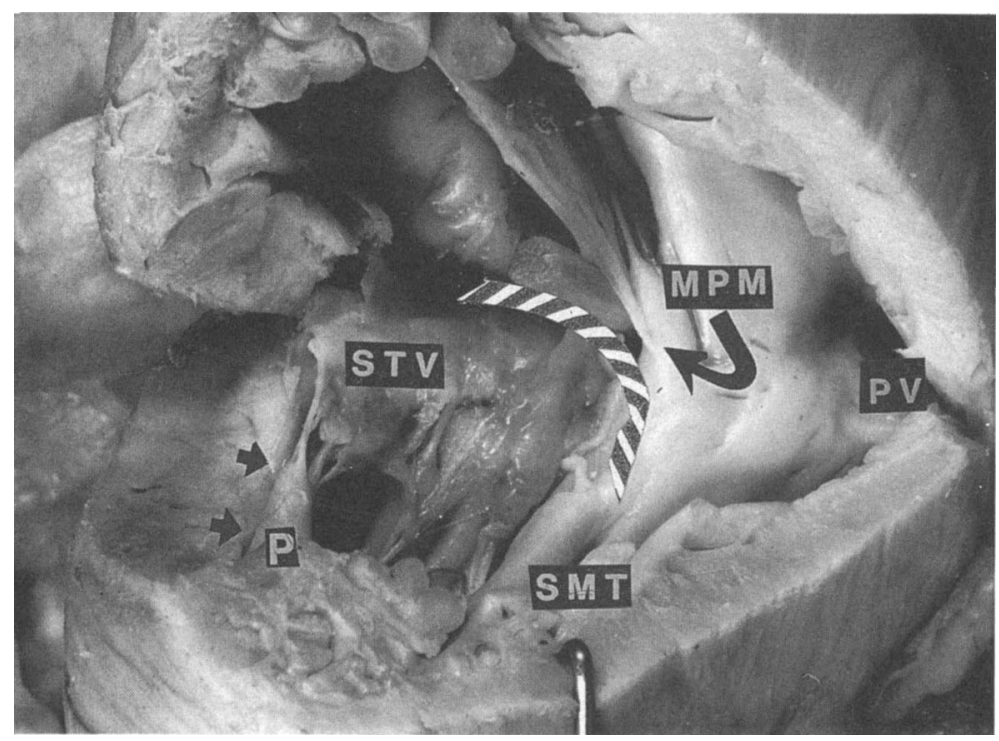

Fig. 3. Right ventricle of heart with normal segmental connections. Muscular ventricular septal defect lies between medial papillary muscle complex and posterior wall of heart (small arrows); it is partially covered by septal leaflet of tricuspid valve and musculature of posteroseptal papillary muscle complex. This type of defect, opening against posterior wall of heart (also on left side of septum, see Fig. 4) was also seen in the series of hearts with complete transposition. Axis of conduction system (striped band) passes anterosuperiorly to defect. $P V$, Pulmonary valve; for other abbreviations, see Fig. 1.

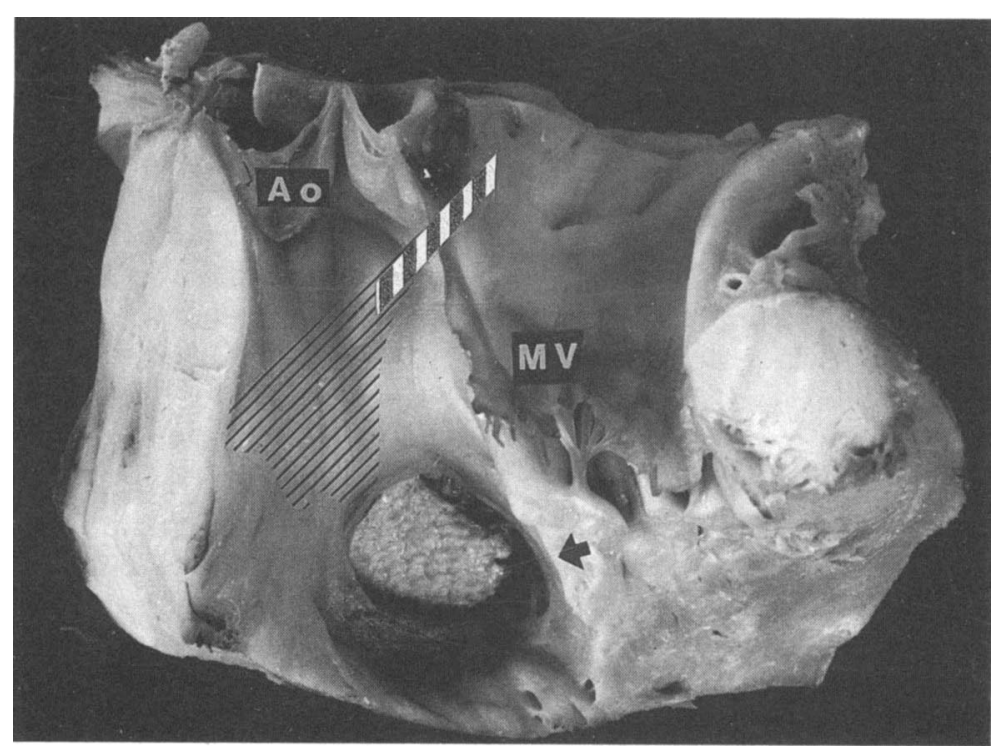

Fig. 4. Left ventricle of specimen in Fig. 3. Ventricular septal defect abuts onto posterior wall of heart (arrow). Axis of conduction system runs anterosuperiotly to defect. $A o$, Aortic valve; $M V$, mitral valve.

major difference in the distribution of the conduction axis discovered by Truex and Bishof, ${ }^{11}$ having confirmed for ourselves these results for hearts with ventricular septal defects in the setting of concordant segmental connections. ${ }^{12}$ Despite this prior knowledge, confirmed again in this present study, we were unable to reconcile the location of the ventricular septal defect held to be typical for complete transposition by Bharati, Lev, and Kirklin ${ }^{14}$ with our present observations. Thus when examining the illustrations of Bharati, Lev, and Kirklin ${ }^{14}$, it is simple to 


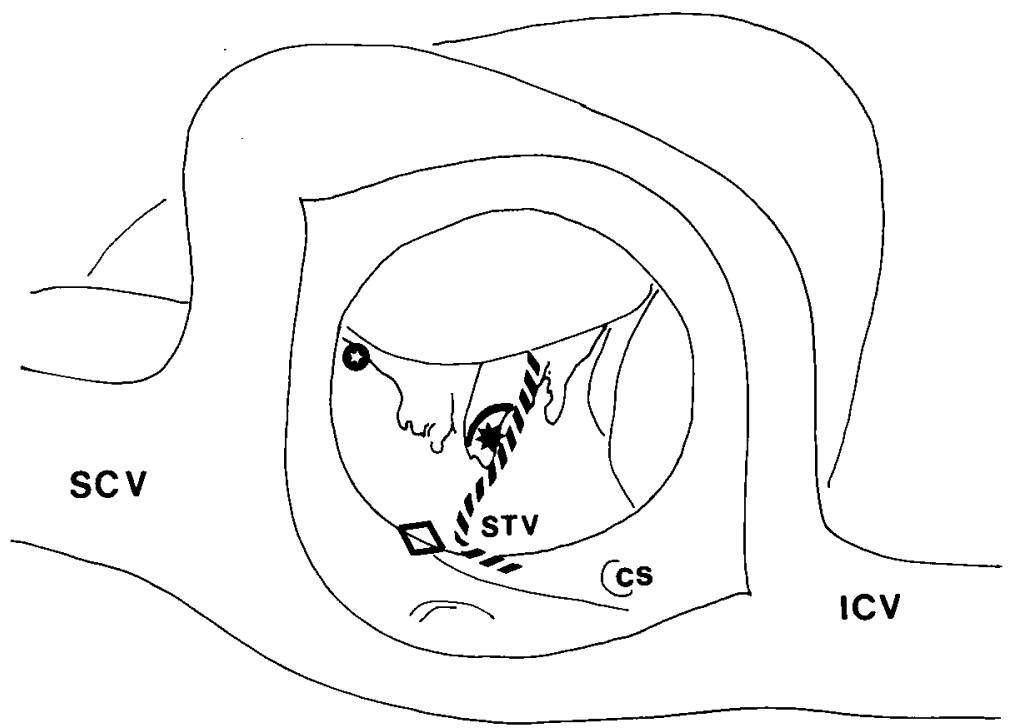

Fig. 5. Approximation of view that the surgeon would have through right atriotomy incision and tricuspid valve. Ventricular septal defect (black asterisk) lies to right of zone of medial papillary muscle complex (of which white asterisk shows anterior extent) but underneath septal leaflet of tricuspid valve and does not extend to posterior wall of heart. Conduction system runs to surgeon's right hand margin of defect. Membranous septum is indicated by diamond. $C S$, Coronary sinus; $I C V$, inferior caval vein; $S C V$, superior caval vein; $S T V$, septal leaflet of the tricuspid valve.

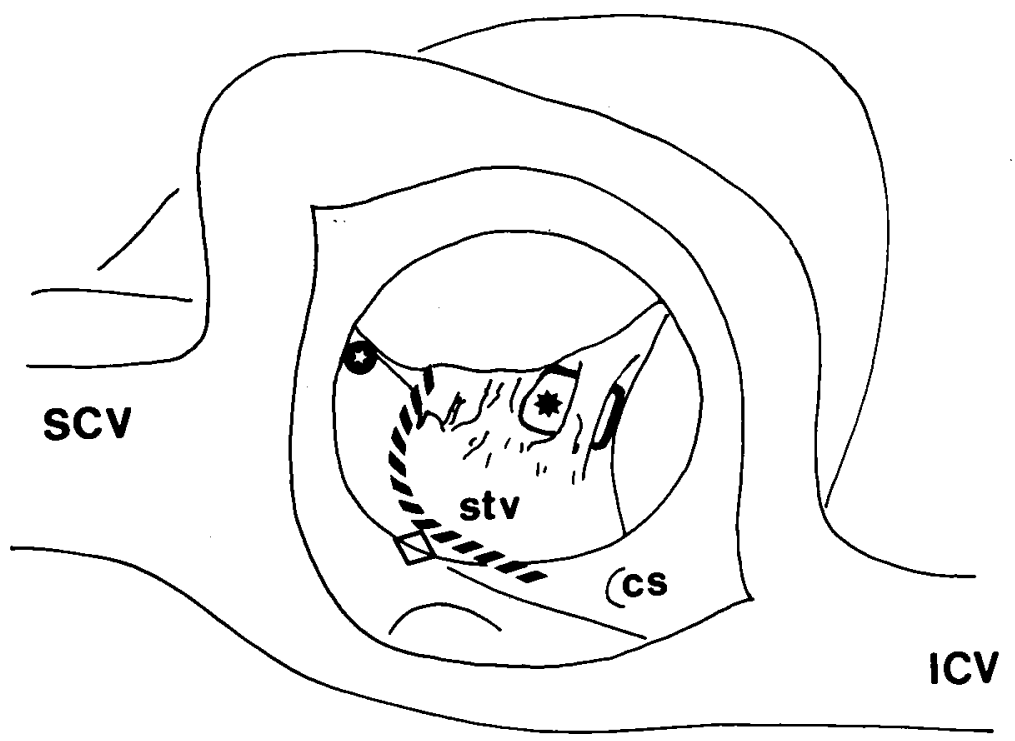

Fig. 6. Approximation of view that the surgeon would have through right atriotomy incision and tricuspid valve. Ventricular septal defect (black asterisk) lies to right of zone of medial papillary muscle complex (of which white asterisk shows anterior extent) but is related to septal leaflet of tricuspid valve. It extends to posterior wall of heart. Conduction system runs to the surgeon's left hand side. For abbreviations see Fig. 5.

discern that the muscular defect in their case 7 is comparable with our muscular defects located between the ventricular inlets ( such defects being found in our hearts both with and without complete transposition). In contrast, having examined the illustrations and descriptions of the right ventricular aspects of their cases $8,9,10$, and 11 with so called infracristal or intracristal defects, we cannot correlate these findings with the defects in our series 
Table II. Course of the conduction tissue in subtricuspid muscular defects

\begin{tabular}{|c|c|c|c|c|c|c|}
\hline & \multicolumn{6}{|c|}{ Specimen No. } \\
\hline & 2061 & $I 256$ & 1173 & 116 & 921 & 108 \\
\hline \multicolumn{7}{|l|}{ VA connection } \\
\hline Concordant & No & No & No & Yes & No & Yes \\
\hline Discordant & Yes & Yes & Yes & No & Yes & No \\
\hline Size $(\mathrm{mm})$ & $7 \times 4$ & $4 \times 1$ & $2 \times 2$ & $8 \times 3$ & $8 \times 4$ & $9 \times 6$ \\
\hline \multicolumn{7}{|l|}{ Location } \\
\hline $\begin{array}{l}\text { Right side, under or } \\
\text { partially under SL }\end{array}$ & Yes & Yes & Yes & Yes & Yes & Yes \\
\hline Left side, subpulmonary & Yes & Yes & Yes & No & No & No \\
\hline $\begin{array}{l}\text { Left side, extending to } \\
\text { posterior wall }\end{array}$ & No & No & No & Yes & Yes & Yes \\
\hline \multicolumn{7}{|l|}{ NBB } \\
\hline Intramyocardial & Yes & No & No & No & No & Yes \\
\hline Subendocardial & No & Yes & Yes & Yes & Yes & No \\
\hline \multicolumn{7}{|l|}{ Bifurcation } \\
\hline Intramyocardial & No & No & No & No & No & Yes \\
\hline Subendocardial & Yes & Yes & Yes & Yes & Yes & No \\
\hline Bifurcation on rim of defect & Yes & No & No & No & No & No \\
\hline \multicolumn{7}{|l|}{ Proximal RBB } \\
\hline Intramyocardial & No & Yes & Yes & Yes & Yes & Yes \\
\hline Subendocardial & Yes & No & No & No & No & No \\
\hline \multicolumn{7}{|l|}{ Distal RBB } \\
\hline Intramyocardial & Yes & Yes & Yes & No & No & No \\
\hline Subendocardial & No & No & No & Yes & Yes & Yes \\
\hline $\mathrm{CT}$ to left hand margin & No & No & No & Yes & Yes & Yes \\
\hline $\mathrm{CT}$ to right hand margin & Yes & Yes & Yes & No & No & No \\
\hline
\end{tabular}

$V A$, Ventriculoarterial; $S L$, septal leaflet of tricuspid valve; $N B B$, nonbranching bundle; $R B B$, right bundle branch; $C T$, conduction tissue

described as subpulmonary and subtricuspid. As far as we can judge, the illustrations of the left ventricular aspect of the defects studied by Bharati and Lev ${ }^{13}$ show that the posteroinferior margins run to the area of fibrous continuity between the leaflets of the mitral and pulmonary valves. If this is the case, then the defects are perimembranous and not comparable with the particular subtricuspid and subpulmonary muscular defects, which are the subject of this study. This distinction is more important because Bharati, Lev, and Kirklin ${ }^{14}$ have selected only two types of defects in complete transposition as worthy for illustration with respect to the atrioventricular conduction axis, describing the posterior course relative to the perimembranous defect and the anterior course relative to the muscular inlet defect. The subtricuspid and subpulmonary muscular defect described in the present study appears at first sight to be a muscular inlet defect, yet bears the relationship to the conduction axis as expected for the perimembranous defect.

We recognize that it is foolhardy to argue that a certain defect found in one class of malformations cannot exist in another group. Despite this caveat, we still believe that the particular subpulmonary and subtricuspid defects we have presently found in the hearts with com- plete transposition (and seeming at first sight, when viewed from the right ventricle, to be a muscular inlet defect) have no counterpart in hearts with concordant ventriculoarterial connections. It is also our belief that the surgeon reading the extant works concerning the location of the atrioventricular conduction axis relative to ventricular septal defects ${ }^{10,13}$ could well draw the conclusion that the anterosuperior margin (surgeon's left hand) of the defect would be at risk rather than the posteroinferior margin (surgeon's right hand).

A variety of muscular ventricular septal defects, therefore, is to be found in the setting of complete transposition, some of which have common landmarks. These are the medial and posteroseptal papillary muscle complexes which lie to the left and right hand rims of the defect, respectively. When the right hand margin of the defect directly approaches the posterior wall of the heart, the axis of atrioventricular conducting tissue runs anterosuperiorly (or to the surgeon's left hand) to the defect, which is of the muscular inlet variety. In contrast, when the right hand rim does not run to the posterior wall and the subtricuspid defect opens in a subpulmonary position in the left ventricle, the atrioventricular axis runs to the surgeon's right hand. Definition of the position of the defect 
on the left side of the septum, therefore, will be definitive in distinguishing between the two types in a clinical setting. Direct assessment unfortunately, is not offered to the surgeon, but, rather, the feature should readily be distinguished by cross-sectional echocardiography.

Although ventricular septal defect has often been considered to complicate the surgical treatment of complete transposition, we have not been able to find any reference to postoperative heart block occurring in association with repair of muscular defects. It is possible that this defect, lying as it does in proximity to the anteroseptal commissure of the tricuspid valve and to the membranous septum, has not been recognized as being muscular but has been diagnosed as a perimembranous defect in both the preoperative and intraoperative periods. If this assessment is true, then, by default, the axis of the conducting system has been correctly interpreted as running on or close to the right hand margin. Additionally, the long nonbranching bundle in these hearts would have been protected from surgical trauma by running either on the left side of the septum or intramuscularly.

These findings emphasize that classic and relatively simple subcategorizations of ventricular septal defect may not always be adequate for assessing the position of the atrioventricular conduction system. It behooves the surgeon to keep an open mind on the anatomic details during surgery, assessing as best he can the landmarks but coupling these with detailed cross-sectional echocardiographic findings obtained both in the preoperative and intraoperative periods.

We thank M. Pozzi for his interest in the work, Sandra Longworth for typing the manuscript, and Ken Walters for producing the photographic prints.

\section{REFERENCES}

1. Becu LM, Fontana RS, Du Shane JW, Kirklin JW, Burchell HB, Edwards JE. Anatomic and pathologic studies in ventricular septal defect. Circulation 1956;14:349-64.

2. Warden HE, De Wall RA, Cohen M, Varco RL, Lillehei CW. A surgical-pathologic classification for isolated ventricular septal defects and for those in Fallot's tetralogy based on observations made on 120 patients during repair under direct vision. J THORAC CARDIOvaSC SURG 1957; 33:21-4.

3. Kirklin JW, Harshbarger HG, Donald DE, Edwards JE. Surgical correction of ventricular septal defect: anatomic and technical considerations. J THORAC CARDIOvaSC SURG 1957;33:45-9.

4. Goor DA, Lillehei CW. Septal defects. In: Congenital malformation of the heart: embryology, anatomy. Operative considerations. New York: Grune and Stratton, 1978:113-24.

5. Wenink ACG, Oppenheimer-Dekker A, Moulaert AJ. Muscular ventricular septal defects: a reappraisal of the anatomy. Am J Cardiol 1979;43:259-64.

6. Soto B, Becker AE, Moulaert AJ, Lie JT, Anderson RH. Classification of ventricular septal defects. Br Heart J 1980;43:332-43.

7. Capelli H, Andrade JL, Somerville J. Classification of the site of ventricular septal defect by 2-dimensional echocardiography. Am J Cardiol 1983;51:1474-80.

8. Soto B, Ceballos R, Kirklin JW. Ventricular septal defects: a surgical viewpoint. JACC 1981;5:1291-7.

9. Anderson RH, Becker AE, Tynan M. Description of ventricular septal defects-or how long is a piece of string? Editorial review. Int J Cardiol 1986;13:267-78.

10. Anderson RH, Wilcox BR. The surgical anatomy of ventricular septal defect. J Cardiac Surg 1992;7:17-35.

11. Truex RC, Bishof JK. Conduction system in human hearts with interventricular septal defects. J THORAC CARDIOvASC SURG 1958;35:421-39.

12. Latham RA, Anderson RH. Anatomical variations in the atrioventricular conduction system with reference to ventricular septal defects. Br Heart J 1972;34:185-90.

13. Bharati $\mathrm{S}$, Lev $\mathrm{M}$. The conduction system in simple, regular (d-), complete transposition with ventricular septal defect. J Thorac Cardiovasc Surg 1976;2:194-201.

14. Bharati S, Lev M, Kirklin JW. Operations in the right atrium: the relevance of the conduction system in arterial switch repair in complete transposition with ventricular septal defect. In: Cardiac surgery and the conduction system. 2nd ed. Mount Kisco, New York: Futura 1992:62-68.

15. Smith A, Ho SY, Anderson RH. Histological study of the cardiac conducting system as a routine procedure. Med Lab Sci 1977;34:223-9.

16. Kurosawa H, Van Mierop LHS. Surgical anatomy of the infundibular septum in transposition of the great arteries with ventricular septal defect. J THORAC CARDIOvasC SURG 1986;91:123-32.

17. Moene RJ, Oppenheimer-Dekker A, Bartelings MM, Wenink ACG, Gittenberger de Groot AC. Ventricular septal defect with normally connected and with transposed great arteries. Am J Cardiol 1986;58:627-32.

18. Hoyer MH, Zuberbuhler JR, Anderson RH, del Nido P. Morphology of ventricular septal defects in complete transposition: surgical implications. J THORAC CARDIOvasC SURG 1992;104:1203-11.

19. Moene RJ, Oppenheimer-Dekker MD, Wenink ACG, Bartelings MM, Gittenberger de Groot AC. Morphology of ventricular septal defect in complete transposition of the great arteries. Am J Cardiol 1985;55:1566-70. 